\title{
TROCAS GASOSAS E CONDUTÂNCIA ESTOMÁTICA EM DUAS ESPÉCIES DE TRIGO EM DIFERENTES TEORES DE ÁGUA NO SOLO ${ }^{1}$
}

\author{
REGINA MIYUKI SASSAKI ${ }^{2}$ e EDUARDO CARUSO MACHADO ${ }^{3}$
}

\begin{abstract}
RESUMO - Neste trabalho teve-se como objetivo comparar o efeito da variação do teor de água no solo sobre as trocas gasosas e relações hídricas em duas espécies de trigo (Triticum aestivum L., trigo normal, e Triticum durum L., trigo duro). As plantas foram deixadas crescer em casa de vegetação em vasos de $0,13 \mathrm{~m}$ de diâmetro por $0,3 \mathrm{~m}$ de altura, e as medidas de assimilação de $\mathrm{CO}_{2}$, o potencial de água na folha, a condutância estomática e a transpiração foram feitas sob condições controladas (DFFFA $=800 \mu \mathrm{mol} \mathrm{m} \mathrm{m}^{-2} \mathrm{~s}^{-1}, \mathrm{~T}=28^{\circ} \mathrm{C}$ ). Os potenciais de água na folha variaram entre $-0,3$ e $-2,4$ e $-0,3$ e -2,8 $\mathrm{MPa}$, respectivamente, em trigo normal e trigo duro. A assimilação de $\mathrm{CO}_{2}$, tendo em vista a variação do potencial de água na folha, apresentou diferenças tanto em relação ao padrão de resposta quanto à tolerância à deficiência hídrica. Em trigo normal, a assimilação de $\mathrm{CO}_{2}$ foi nula em potencial da água da folha, ao redor de $-2,4 \mathrm{MPa}$, enquanto no trigo duro a assimilação de $\mathrm{CO}_{2}$ foi ao redor de $4 \mu \mathrm{mol} \mathrm{m}^{-2} \mathrm{~s}^{-1}$ em potencial de $-2,8 \mathrm{MPa}$. Discute-se o possível efeito direto do dessecamento do solo sobre a abertura estomática.
\end{abstract}

Termos para indexação: fotossíntese, potencial de água na folha, tolerância à seca, taxa de transpiração, Triticum aestivum, Triticum durum.

\section{GAS EXCHANGE AND STOMATAL CONDUCTANCE OF TWO WHEAT SPECIES AT DIFFERENT SOIL WATER CONTENTS}

\begin{abstract}
The objective of this work was to compare gas exchange rates and water status of two wheat species (Triticum aestivum L., "trigo normal", and Triticum durum L., "trigo duro") at different soil water contents. Plants were grown under greenhouse conditions in $0.13 \mathrm{~m}$ diameter, $0.30 \mathrm{~m}$ deep pots containing soil and during the period of grain development plants were submitted to water deficiency. So, $\mathrm{CO}_{2}$ assimilation rate, leaf water potential, stomatal conductance and transpiration rate were measured under controlled conditions (PPFD $=800 \mu \mathrm{mol} \mathrm{m}^{-2} \mathrm{~s}^{-1}, \mathrm{~T}=28^{\circ} \mathrm{C}$ ). Water potential ranged from -0.3 to -2.4 and from -0.3 to $-2.8 \mathrm{MPa}$, in "trigo normal" and "trigo duro", respectively. $\mathrm{CO}_{2}$ assimilation rate as a function of leaf water potential presented differences between the two species in terms of response pattern and tolerance to water deficit. In "trigo normal", $\mathrm{CO}_{2}$ assimilation rate was zero when water potential was around -2.4 $\mathrm{MPa}$, while in "trigo duro" this was around $4 \mu \mathrm{mol} \mathrm{m} \mathrm{m}^{-2} \mathrm{~s}^{-1}$ when leaf water potential was around $-2.8 \mathrm{MPa}$. Dry soil may potentially affect stomatal aperture.
\end{abstract}

Index terms: photosynthesis, leaf water potential, drought tolerance, transpiration rate, Triticum aestivum, Triticum durum.

\footnotetext{
${ }^{1}$ Aceito para publicação em 3 de agosto de 1998.

${ }^{2}$ Bióloga, Dra ${ }^{\text {a }}$, Seção de Fisiologia e Bioquímica de Plantas, Instituto de Botânica, Caixa Postal 4005, CEP 01061-970 São Paulo, SP. Bolsista do CNPq.

${ }^{3}$ Eng. Agr., Dr., Seção de Fisiologia, Instituto Agronômico (IAC), Caixa Postal 28, CEP 13001-970 Campinas, SP. Bolsista do CNPq. E-mail: caruso@barao.iac.br
}

\section{INTRODUÇÃO}

O trigo cultivado no Brasil pertence à espécie Triticum aestivum L., com características adequadas para sua utilização em panificação. O trigo duro ou trigo para macarrão (Triticum durum L.), apresenta características adequadas à indústria de 
pastas alimentares, mas praticamente não é cultivado no Brasil. A partir de 1984, iniciou-se no Instituto Agronômico de Campinas um programa de melhoramento do trigo duro (Camargo et al., 1995a, 1995b). As cultivares e linhagens de trigo duro resultantes deste programa estão sendo avaliados em relação a várias características, como: produtividade, tolerância a doenças e pragas, qualidades da matéria-prima produzida, e outras (Camargo et al., 1995a, 1995b).

O trigo duro, sendo uma cultura de inverno, está sujeito à ocorrência de seca. A deficiência hídrica é um dos fatores abióticos que mais afetam a estabilidade produtiva das culturas. Em trigo, a ocorrência de deficiência hídrica em vários estádios de desenvolvimento afeta sua produtividade e crescimento (Gusta \& Chen, 1987), reduzindo severamente a taxa de assimilação de $\mathrm{CO}_{2}$ (Wardlaw, 1971; Machado et al., 1993). A ocorrência de deficiência hídrica nas fases próximas à floração e no estádio de crescimento de grãos diminuiu em $30 \%$ a produção de trigo IAC-60, devido, principalmente, à queda na taxa de assimilação de $\mathrm{CO}_{2}$ (Machado et al., 1993).

A redução na assimilação de $\mathrm{CO}_{2}$ pode ser devida ao fechamento do estômato, restringindo o influxo de $\mathrm{CO}_{2}$ nas células do mesófilo. Os estômatos podem responder rapidamente, dependendo da umidade do ar ou do solo (Turner et al., 1985). Embora o fechamento dos estômatos durante o dessecamento do solo coincida com a queda no potencial de água na folha, vários experimentos também têm demonstrado decréscimos na condutância estomática, mesmo que o potencial de água na folha seja mantido constante (Davies et al., 1986; Gollan et al., 1986). Tal comportamento sugere que durante o dessecamento do solo as raízes podem agir diretamente sobre o controle estomático, por meio de um sinal químico produzido pelas próprias raízes (Davies et al., 1990). Também há evidências de que a desidratação, além de afetar a fotossíntese devido à restrição ao fluxo de $\mathrm{CO}_{2}$, tem efeitos prejudiciais diretamente sobre o aparelho fotossintético (Kaiser, 1987). Austin et al. (1982) e Johnson et al. (1987) observaram diferenças significativas nas taxas de assimilação de $\mathrm{CO}_{2}$ entre as diferentes espécies de trigo.

Pesq. agropec. bras., Brasília, v.34, n.9, p.1571-1579, set. 1999
Neste trabalho, analisaram-se comparativamente os efeitos da deficiência hídrica sobre as trocas gasosas e o potencial de água na folha, tendo em vista o dessecamento progressivo do solo, em plantas de trigo.

\section{MATERIAL E MÉTODOS}

Foram utilizadas sementes de duas espécies de trigo Triticum aestivum L. (trigo normal, IAC-60) e Triticum durum L. (trigo duro, IAC-1003).

As plantas foram cultivadas em casa de vegetação, em recipientes de $0,13 \mathrm{~m}$ de diâmetro por $0,30 \mathrm{~m}$ de profundidade contendo solo. Antes da semeadura, foi efetuada uma adubação com $0,5 \mathrm{~g}$ de sulfato de amônio, $0,1 \mathrm{~g}$ de superfosfato simples, $0,024 \mathrm{~g}$ de cloreto de potássio, 2,5 $\mathrm{mg}$ de borax e $5 \mathrm{mg}$ de sulfato de zinco para cada $\mathrm{kg}$ de terra, de forma que as plantas apresentaram crescimento adequado.

Foram colocadas seis sementes em cada recipiente, a uma profundidade de $0,02 \mathrm{~m}$. Quando as plântulas apresentavam três folhas, efetuava-se o desbaste, deixando-se três plantas em cada recipiente.

As plantas foram irrigadas diariamente até a época da emergência total das espigas. Neste estádio do crescimento foram efetuados os seguintes tratamentos, em ambas as espécies: o controle, em que as plantas foram irrigadas diariamente com quantidade suficiente para repor a água perdida por evapotranspiração durante um dia; e tratamento de deficiência hídrica em que somente $50 \%$ da água evapotranspirada era reposta diariamente. Esses tratamentos foram feitos por um período suficiente para que a fotossíntese fosse praticamente nula, em pelo menos uma das duas espécies. O consumo médio diário de água (transpiração+evaporação) pelas plantas por vaso foi determinado por um período de cinco dias em 10 vasos, para cada espécie, pela diferença entre a massa da terra úmida (capacidade de campo) e a massa da terra no dia seguinte, antes da nova irrigação. Calculou-se, desta forma, um consumo médio de, aproximadamente, $250 \mathrm{~mL}$ de água dia $^{-1}$ vaso $^{-1}$.

Medidas comparativas da taxa de assimilação de $\mathrm{CO}_{2}$, da taxa de transpiração, do potencial de água na folha, da condutância estomática e da umidade da terra nos vasos foram feitas diariamente, nas plantas das duas espécies, por um período de seis dias a partir do início do processo de imposição da deficiência hídrica. A cada dia, três vasos de cada tratamento (nove plantas/tratamento) foram transferidos da casa de vegetação para o laboratório, onde foram mantidos sob fonte de luz artificial (quatro lâmpadas de mercúrio de alta pressão, $400 \mathrm{~W}$ cada) 
e a temperatura constante de $28^{\circ} \mathrm{C}$. Para absorver a radiação de ondas longas e impedir o aumento da temperatura sobre as folhas, foi suspenso, entre as plantas e a fonte de luz, um recipiente de acrílico de $0,12 \mathrm{~m}$ de profundidade contendo água em circulação. As plantas foram mantidas sob esta fonte de luz (densidade de fluxo de fótons fotossinteticamente ativos, DFFFA $=800 \mu \mathrm{mol} \mathrm{m}^{-2} \mathrm{~s}^{-1}$ ) por cerca de duas horas antes do início das medidas, às $12 \mathrm{~h}$. A taxa de assimilação de $\mathrm{CO}_{2}$, a taxa de transpiração e a condutância estomática foram medidas na folha-bandeira de cada planta, utilizando-se um sistema portátil de fotossíntese (LI-6200, LiCor, Inc., Lincoln, NE, USA). Essas variáveis foram analisadas tendo em vista as variações no potencial hídrico da folha e no conteúdo de água do solo.

O potencial de água em todas folhas-bandeira usadas para medidas de trocas gasosas foi determinado com uma bomba de pressão, de acordo com a técnica descrita em Turner (1981).

$\mathrm{O}$ teor de umidade da terra foi obtido a partir de uma amostra de cada recipiente das plantas utilizadas para as medidas citadas acima. Aproximadamente $0,2 \mathrm{~kg}$ de terra foram usados para obtenção da massa úmida (logo após as medidas de trocas gasosas) e da massa seca ( 72 horas a $105^{\circ} \mathrm{C}$ ) e o teor de umidade expresso em porcentagem.

\section{RESULTADOS E DISCUSSÃO}

A Fig. 1 ilustra a seqüência de eventos que ocorreram durante a imposição da deficiência hídrica nas plantas de duas espécies de trigo (Triticum aestivum L., cv. IAC-60 e Triticum durum L., cv. IAC-1003, respectivamente trigo normal e trigo duro), crescidos em casa de vegetação. $\mathrm{O}$ teor de umidade da terra, nos vasos em que a reposição foi de somente $50 \%$ da água evapotranspirada, diminuiu de 16 para $8,5 \%$ no período de seis dias. Nos vasos em que houve reposição total da água, o teor de umidade da terra foi mantido entre 15 e $16 \%$ durante o período experimental (Fig. 1d). A queda do teor de umidade da terra nos vasos seguiu um padrão quantitativamente semelhante, indicando que nestas condições o consumo de água foi semelhante em ambas espécies.

Em ambas as espécies, sem deficiência hídrica, as variáveis medidas apresentaram valores e padrões de respostas semelhantes (Fig. 1). Sem deficiência hídrica, as taxas de assimilação de $\mathrm{CO}_{2}$ foram semelhantes em ambas espécies, e praticamente
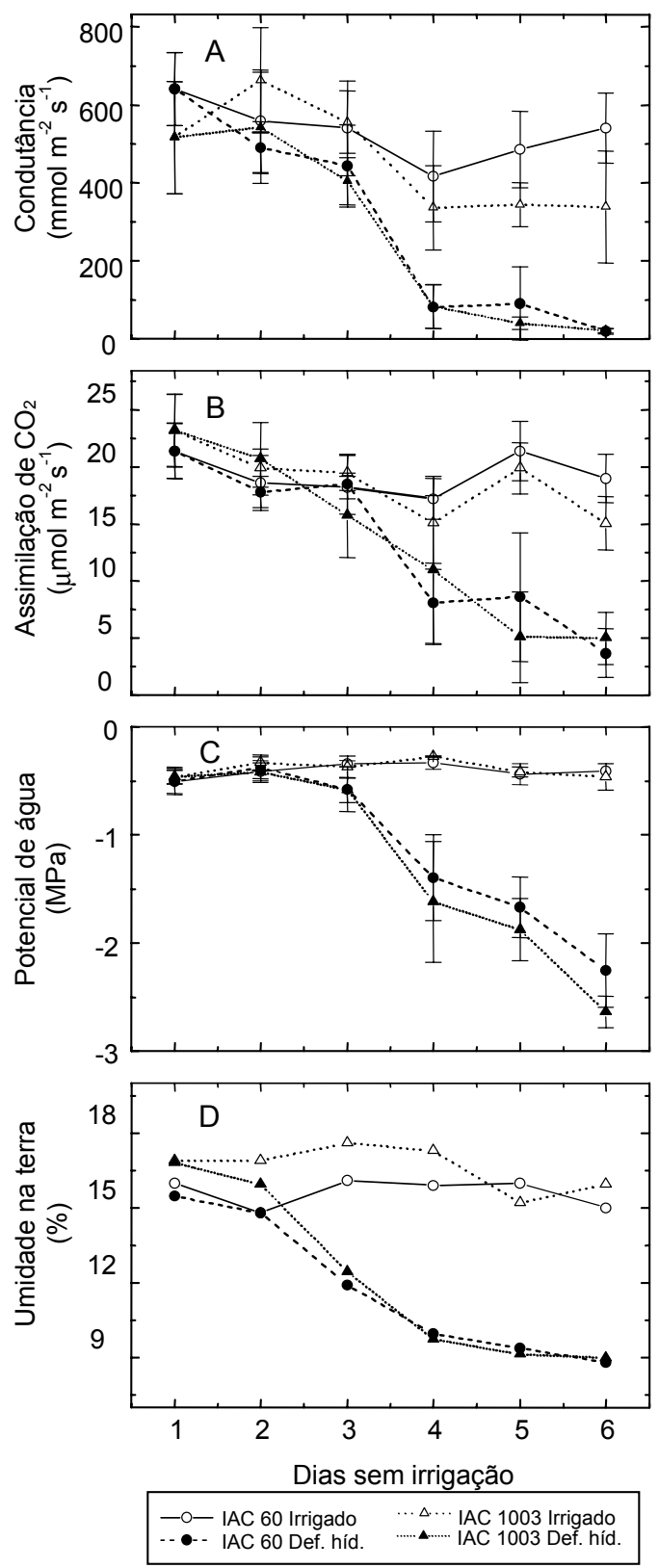

FIG. 1. Condutância estomática (A), taxa de assimilação de $\mathrm{CO}_{2}(\mathrm{~B})$, potencial de água na folha (C) e teor de umidade do solo (D), em duas espécies de trigo (IAC-60, trigo normal, e IAC-1003, trigo duro), em relação ao número de dias sem irrigação. As barras verticais indicam desvios-padrões. Cada ponto representa a média de seis repetições.

Pesq. agropec. bras., Brasília, v.34, n.9, p.1571-1579, set. 1999 
constantes no período experimental. Estes resultados diferem dos obtidos por Austin et al. (1982), que observaram maiores valores na taxa de assimilação de $\mathrm{CO}_{2}$ no trigo duro que no trigo normal.

Apesar de as plantas terem sido cultivadas em casa de vegetação e em vasos, os valores de condutância estomática e das taxas de assimilação de $\mathrm{CO}_{2}$ (Figs.1a e 1b) e de transpiração (Fig. 2a), sob densidade de fluxo de fótons fotossinteticamente ativos saturantes $\left(\sim 800 \mu \mathrm{mol} \mathrm{m} \mathrm{m}^{-2} \mathrm{~s}^{-1}\right)$, foram semelhantes aos obtidos em plantas cultivadas sob condições naturais (Machado et al., 1993; Machado \& Lagôa, 1994).

As plantas submetidas a deficiência hídrica, independentemente da espécie, apresentaram padrão de resposta semelhante, tendo em vista o dessecamento da terra, sendo portanto analisadas em conjunto. Apesar de o decréscimo do teor de umidade do solo ter-se iniciado já no segundo dia de suspensão parcial da irrigação (Fig. 1d), o potencial de água na folha (Fig. 1c) e a taxa de assimilação de $\mathrm{CO}_{2}$ (Fig. 1b) mantiveram-se praticamente os mesmos até o terceiro dia; porém, a condutância estomática decaiu (Fig. 1a). Tal comportamento sugere que mesmo sob queda rápida da umidade do solo, a abertura estomática respondeu mais rapidamente à variação do conteúdo de água no solo do que ao potencial da água na folha. Este comportamento pode ter ocorrido em resposta a um sinal captado e emitido pelas raízes, conforme foi sugerido no tocante ao girassol, milho e outras espécies (Turner et al., 1985; Gollan et al., 1986; Zhang \& Davis, 1987). A natureza do sinal emitido é motivo de muitos debates, porém há indicações que o relacionam com a produção, transporte e redistribuição do ácido abscísico (Zhang \& Davis, 1987, 1990).

Após o terceiro dia de secagem do solo, a condutância estomática, a taxa de assimilação de $\mathrm{CO}_{2}$ e o potencial da água na folha caíram acentuada e proporcionalmente. Os valores mínimos atingidos pelo potencial de água nas folhas foram de $-2,4 \mathrm{e}$ $-2,8 \mathrm{MPa}$, respectivamente, no tocante ao trigo normal e duro. Sob condições naturais, em plantas adultas, o desenvolvimento da deficiência hídrica pode ocorrer de forma mais lenta que no caso presente, dependendo do estádio de crescimento da planta (Frank et al., 1973) e da demanda atmosférica. As diferentes velocidades de imposição da deficiência hídrica causam diferentes efeitos sobre a fotossíntese, relações hídricas e estratégias de escape (Kaiser, 1987; Saccardy et al., 1996),

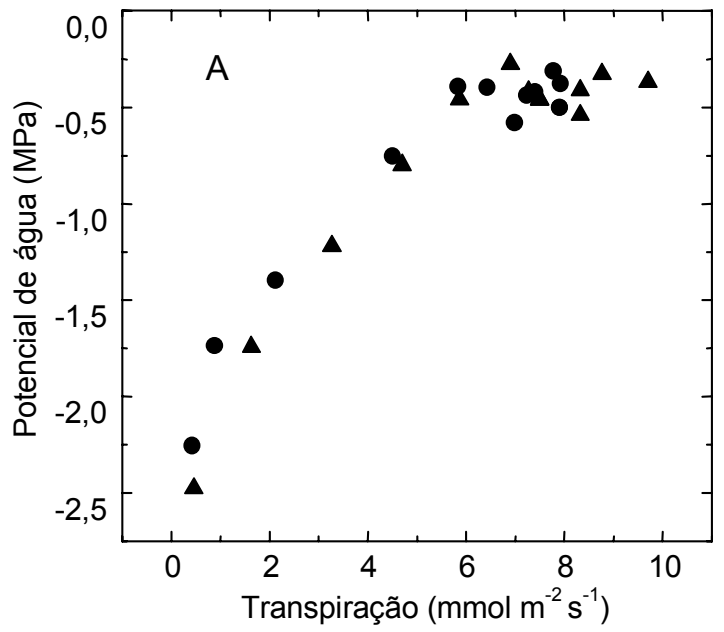

- IAC-60

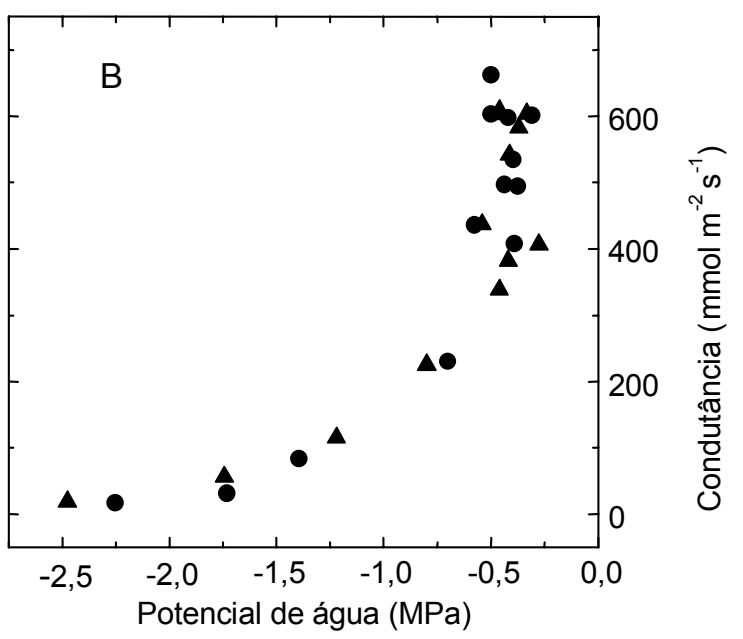

- IAC-1003

FIG. 2. Relações entre taxa de transpiração e potencial de água na folha (A) e condutância estomática e potencial da água na folha (B) em plantas de duas espécies de trigo (trigo normal, IAC-60, e trigo duro, IAC-1003) submetidas a dessecamento do solo. Cada ponto representa a média de 5 a 6 repetições. 
razão pela qual a extrapolação das respostas da fotossíntese à deficiência hídrica deve considerar as condições em que se efetuaram as medidas.

A Fig. 2 ilustra a resposta da transpiração e da condutância estomática em relação à variação do potencial de água na folha, em face do dessecamento da terra. A despeito de as espécies serem diferentes, os resultados observados em relação a estas duas variáveis foram semelhantes. No início do dessecamento do solo, quando os valores dos potenciais de água nas folhas variaram entre $-0,3 \mathrm{e}$ $-0,5 \mathrm{MPa}$, houve grande variação na condutância estomática e na transpiração (Figs. 2a e 2b). Em valores abaixo de $-0,5 \mathrm{MPa}$, a queda destas duas variáveis foi praticamente linear, tendendo a zero.

As variações na condutância e na transpiração, na faixa de potencial da água na folha entre $-0,3$ e $-0,5 \mathrm{MPa}$, talvez estejam relacionadas ao efeito direto da queda da umidade do solo sobre os estômatos, como também foi sugerido por Turner et al. (1985). Verifica-se, na Fig. 3, que o potencial de água na folha variou menos que a condutância estomática e a taxa de assimilação de $\mathrm{CO}_{2}$, graças à umidade do solo na faixa de 16 e 12,5\%. Este tipo de comportamento da condutância e do potencial de água na folha, tendo em vista o teor de umidade do solo, também foi observado em relação a outras espécies (Turner et al., 1985; Gollan et al., 1986). Por outro lado, Johnson et al. (1974), observaram, em trigo normal, queda linear da transpiração entre valores de potencial de água na folha de $-0,3$ a $-3,0 \mathrm{MPa}$.

Também, em ambas as espécies, a taxa de assimilação de $\mathrm{CO}_{2}$ e o potencial de água na folha variaram pouco, em teores de umidade da terra, ao redor de $12 \%$ (Fig. 3), o que mostra que a queda da condutância em deficiências moderadas de água na terra (Figs. 2b e 3a) não afetam significativamente a assimilação de $\mathrm{CO}_{2}$ nem a fotossíntese em si. Deficiências moderadas podem afetar a produção fotossintética se ela afetar o desenvolvimento da área foliar (Hsiao \& Bradford, 1983). A elongação e crescimento são mais sensíveis à queda do potencial de água que a fotossíntese (Boyer, 1970).

A Fig. 4 mostra a comparação da taxa de assimilação de $\mathrm{CO}_{2}$ em face do potencial de água na folha, nas duas espécies de trigo. Neste caso, os padrões de resposta foram diferentes. No trigo normal, a taxa de assimilação de $\mathrm{CO}_{2}$ decresceu linearmente com a queda do potencial de água,
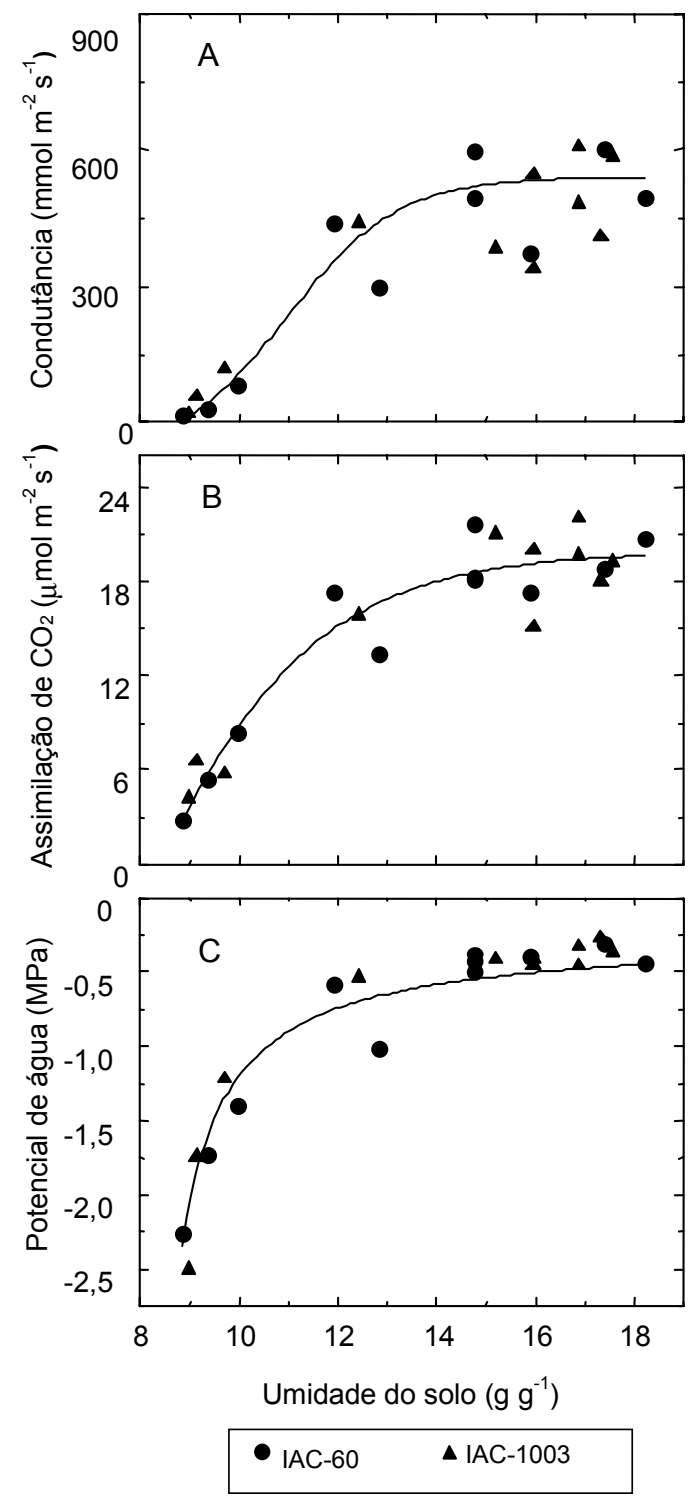

FIG. 3. Variações da condutância estomática (A) da taxa de assimilação de $\mathrm{CO}_{2}(\mathrm{~B})$ e do potencial da água na folha $(C)$, em duas espécies de trigo (trigo normal, IAC-60, e trigo duro, IAC-1003) em relação ao teor de umidade da terra. Cada ponto representa a média de 5 a 6 repetições.

Pesq. agropec. bras., Brasília, v.34, n.9, p.1571-1579, set. 1999 
atingindo valores nulos, ao redor de $-2,4 \mathrm{MPa}$ (Fig. 4b). Em relação ao trigo duro, a queda na taxa de assimilação de $\mathrm{CO}_{2}$, até ao redor de $-1,25 \mathrm{MPa}$, foi mais acentuada que no trigo normal. Depois, em valores de potencial menores, a assimilação de $\mathrm{CO}_{2}$ diminuiu vagarosamente até $-2,8 \mathrm{MPa}$, atingindo valores ao redor de $4 \mu \mathrm{mol} \mathrm{m}{ }^{-2} \mathrm{~s}^{-1}$. Johnson et al. (1974), em trigo normal, suspenderam a irrigação por sete dias no período após a emergência das espigas, e relataram que o potencial de água na folha decresceu até $-3,3 \mathrm{MPa}$ e a taxa de assimilação de $\mathrm{CO}_{2}$ decaiu linearmente. Como o potencial de água na folha e a condutância estomática, em ambas espécies, variaram de forma semelhante com o dessecamento da terra (Fig. 3), é possível que a diferença de comportamento da fotossíntese em trigo duro sob estresse (Fig. 4) esteja relacionada com a manutenção de maior atividade do aparelho fotossintético. Kaiser (1987) discute a existência de diferenças intervarietais e interespecíficas na atividade fotossintética. Johnson et al. (1987) observaram que Triticum kotschyi (tetraplóide) também manteve maior taxa de assimilação de $\mathrm{CO}_{2}$ que o Triticum aestivum sob deficiência hídrica, devido à manutenção da maior capacidade da fotossíntese em T. kotschyi.
A Fig. 5 mostra a resposta da taxa de assimilação de $\mathrm{CO}_{2}$ e da taxa de transpiração, tendo em vista a variação da condutância estomática, causada pelo dessecamento da terra. Como foi visto, a transpiração e a assimilação de $\mathrm{CO}_{2}$ variaram em intensidade e padrão diferentes em decorrência da condutância, conforme relatado também por outros autores (Cowan \& Troughton, 1971; Machado \& Lagôa, 1994). A relação entre condutância e transpiração foi próxima à linearidade, ao passo que a resposta da assimilação de $\mathrm{CO}_{2}$, decorrente da condutância, apresentou uma forma hiperbólica, em que a assimilação tendeu a uma assíntota em valores acima de $300 \mathrm{mmol} \mathrm{m}^{-2} \mathrm{~s}^{-1}$. Quanto a valores acima deste, o aumento da assimilação de $\mathrm{CO}_{2}$ foi somente marginal, ao passo que o da transpiração foi linear. Este padrão de resposta também foi relatado no tocante a trigo, quando a variação da condutância foi devida à variação da densidade de fluxo de fótons fotossinteticamente ativos e não à deficiência hídrica (Machado \& Lagôa, 1994), o que sugere que na faixa de deficiência hídrica utilizada, a restrição ao fluxo de $\mathrm{CO}_{2}$ causada pela queda da condutância foi o principal fator a afetar a taxa de assimilação de $\mathrm{CO}_{2}$. Vários autores sugerem que a depressão da taxa de assimilação de $\mathrm{CO}_{2}$ em deficiência hídrica

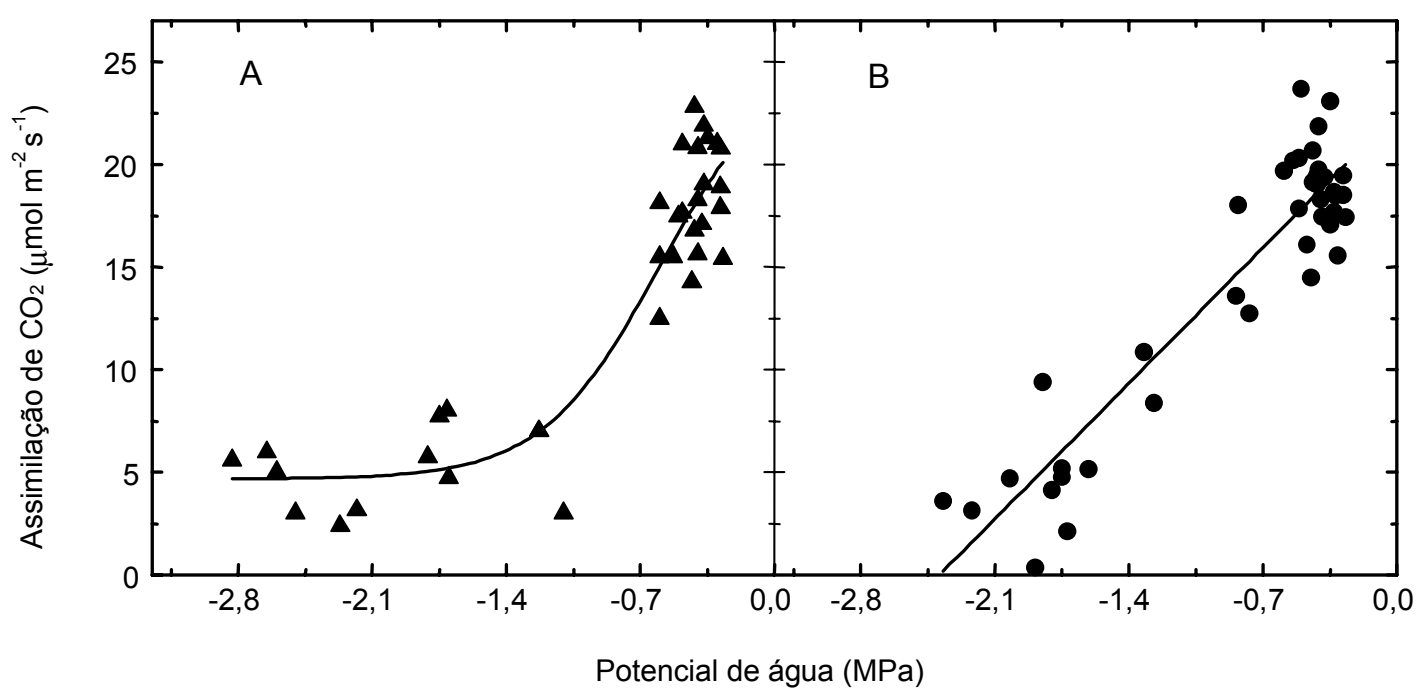

FIG. 4. Resposta da taxa de assimilação de $\mathrm{CO}_{2}$ tendo em vista a variação do potencial de água na folha, em trigo duro, IAC-1003 (A), e trigo normal, IAC-60 (B), submetidas ao dessecamento do solo. 


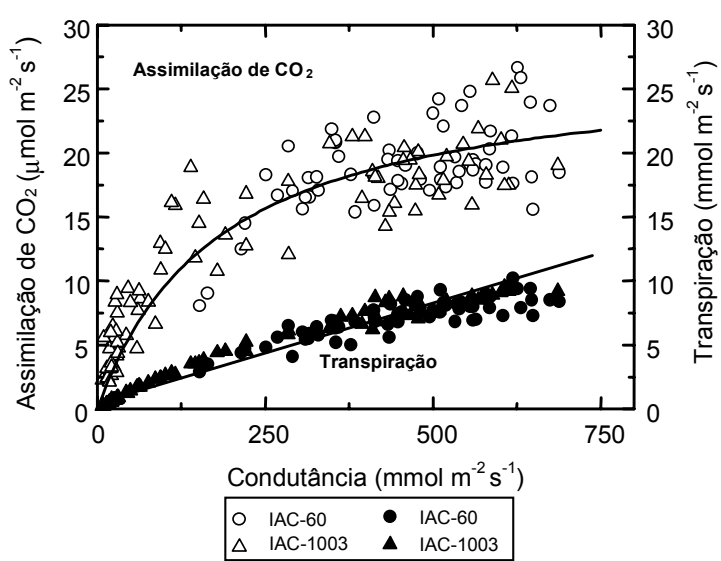

FIG. 5. Relação entre taxa de assimilação de $\mathrm{CO}_{2} \mathrm{e}$ transpiração tendo em vista a condutância estomática em duas espécies de trigo (trigo normal, IAC-60, e trigo duro, IAC-1003), em plantas submetidas ao dessecamento do solo.

moderada é devida principalmente ao fechamento do estômato (Kaiser, 1987; Chaves, 1991; Saccardy et al., 1996). De fato, dependendo da espécie e da natureza da desidratação, mesmo com queda da assimilação a valores próximos de zero, não há evidências que mostrem queda na capacidade fotossintética do mesófilo. Por outro lado, Johnson et al. (1974) relataram, no tocante a trigo normal, que as taxas de ambos os processos, fotossíntese e transpiração, responderam linearmente com a queda do potencial de água na folha, em experimento semelhante ao aqui desenvolvido, o que indica a existência de variabilidade no comportamento, mesmo em plantas de mesma espécie.

A Fig. 6 ilustra as conseqüências das respostas diferenciais da assimilação de $\mathrm{CO}_{2}$ e da transpiração. Até a condutância atingir valores ao redor de $300 \mathrm{mmol} \mathrm{m} \mathrm{m}^{-2} \mathrm{~s}^{-1}$, o aumento da assimilação de $\mathrm{CO}_{2}(A)$ foi maior que o da transpiração (E) (Fig. 5), e resultou em aumento da eficiência do uso de água, isto é, aumento da relação $A / E$, como também relataram Machado \& Lagôa (1994), no tocante a trigo, arroze milho. Quanto a valores acima de $300 \mathrm{mmol} \mathrm{m}^{-2} \mathrm{~s}^{-1}$, houve um pequeno aumento da assimilação de $\mathrm{CO}_{2}$, enquanto a transpiração aumentou constantemente, implicando queda da relação $A / E$. Este tipo de resposta indica que nos limites de deficiência hídrica

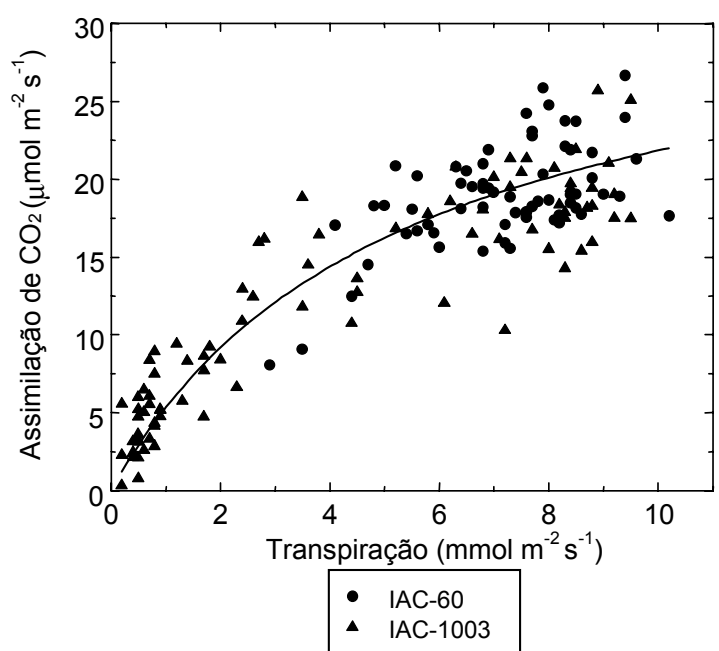

FIG. 6. Relação entre taxa de assimilação de $\mathrm{CO}_{2}$ e taxa de transpiração em duas espécies de trigo (trigo normal, IAC-60, e trigo duro, IAC-1003) submetidas ao dessecamento do solo.

aqui impostos, os estômatos agem no sentido de otimizar a relação $A / E$, como sugerem vários autores (Cowan, 1982; Farquhar \& Sharkey, 1986).

\section{CONCLUSÕES}

1. Em potenciais de água na folha abaixo de $-1,5 \mathrm{MPa}$, a folha-bandeira do trigo duro apresenta maiores taxas de assimilação de $\mathrm{CO}_{2}$ que o trigo normal.

2. Em trigo duro e trigo normal, a queda da taxa de assimilação de $\mathrm{CO}_{2}$ está relacionada principalmente com a queda na condutância estomática.

\section{AGRADECIMENTOS}

Aos Drs. José Guilherme de Freitas e Carlos Eduardo de Oliveira Camargo, do Instituto Agronômico de Campinas, pela colaboração durante a execução deste trabalho.

\section{REFERÊNCIAS}

AUSTIN, R.B.; MORGAN, C.L.; FORD, M.A.; BHAGWAT, S.G. Flag leaf photosynthesis of Triticum aestivum and related diploid and tetraploid species. Annals of Botany, London, v.49, n.2, p.177-189, 1982. 
BOYER, J.S. Differing sensitivity of photosynthesis to low leaf water potential in corn and soybean. Plant Physiology, Lancaster, v.46, n.2, p.236-239, 1970.

CAMARGO, C.E. de O.; FELÍCIO, J.C.; FERREIRA FILHO, J.W.P.; BARROS, B. de C.; PETTINELLI JUNIOR, A.; SANTOS, R.R. Trigo duro, trigo comum e triticale: avaliação de linhagens em condições de irrigação e de soluções nutritivas. Arquivos do Instituto Biológico, São Paulo, v.60, n.1, p.38-47, 1995a.

CAMARGO, C.E. de O.; FELÍCIO, J.C.; SANTOS, R.R.; FERREIRA FILHO, J.W.P. Trigo duro: comportamento de genótipos no Estado de São Paulo. Bragantia, Campinas, v.54, n.2, p.305-317, 1995 b.

CHAVES, M.M. Effects of water deficits on carbon assimilation. Journal of Experimental Botany, Oxford, v.42, n.234, p.1-16, 1991.

COWAN, I.R. Regulation of water use in relation to carbon gain in higher plants. In: LANGE, O.L; NOBEL, P.S.; OSMOND, C.B.; ZIEGLER, H. (Eds.). Physiological plant ecology. II. Water relation and carbon assimilation. Berlin: Springer-Verlag, 1982. p.589-613. (Encyclopedia of plant physiology, v.12B).

COWAN, I.R.; TROUGHTON, J.H. The relative role of stomata in transpiration and assimilation. Planta, Berlin, v.97, p.325-336, 1971.

DAVIES,W.J.; MANSFIELD, T.A. ; HETHERINGTON, A.M. Sensing of soil water status and the regulation of plant growth and development. Plant, Cell and Environment, v.13, n.7, p.709-719, 1990.

DAVIES, W.J.; METCALFE, J.; LODGE, T.A.; COSTA, A.R. da. Plant growth substances and the regulation of growth under drought. Australian Journal of Plant Physiology, Melbourne, v.13, n.1, p.105-125, 1986.

FARQUHAR, G.D.; SHARKEY, T.D. Stomatal conductance and photosynthesis. Annual Review of Plant Physiology, Boca Raton, v.33, p.317-345, 1986.

FRANK, A.B.; POWER, J.F.; WILLIS, W.O. Effect of temperature and plant water stress on photosynthesis, diffusion resistance, and leaf water potential in spring wheat. Agronomy Journal, Madison, v.65, n.5, p.777-780, 1973.

Pesq. agropec. bras., Brasília, v.34, n.9, p.1571-1579, set. 1999
GOLLAN, T.; PASSIOURA, J.B.; MUNNS, R. Soil water status affects the stomatal conductance of fully wheat and sunflower leaves. Australian Journal of Plant Physiology, Melbourne, v.13, n.4, p.459-464, 1986.

GUSTA, L.V.; CHEN, T.H.H. The physiology of water and temperature stress. In: HEYNE, E.G. (Ed.). Wheat and wheat improvement. Madison, Winscosin: American Society of Agronomy, 1987. p.115-150.

HSIAO, T.C.; BRADFORD, K.J. Physiological consequences of cellular water deficits. In: TAYLOR, H.M.; JORDON, W.R.; SINCLAR, T.R. (Eds.). Limitations to efficient water use in crop production. Wisconsin: ASA/ CSSA/ SSSA, 1983. p.227-265.

JOHNSON, R.; FREY, N.M.; MOSS, D.N. Effect of water stress on photosynthesis and transpiration of flag leaves and spikes of barley and wheat. Crop Science, Madison, v.14, n.5, p.728-731, 1974.

JOHNSON, R.; MORNHING, D.W.; FERRIS, D.M.; HEITHOLT, J.J. Leaf photosynthesis and conductance of selected Triticum species at different water potentials. Plant Physiology, Lancaster, v.83, n.4, p.1014-1017, 1987.

KAISER, W.M. Effects of water deficit on photosynthetic capacity. Physiologia Plantarum, Copenhagen, v.71, n.2, p.142-149, 1987.

MACHADO, E.C.; LAGÔA, A.M.M.A. Trocas gasosas e condutância estomática em três espécies de gramíneas. Bragantia, Campinas, v.53, n.2, p.141-149, 1994.

MACHADO, E.C.; LAGÔA, A.M.M.A.; TICCELLI, M. Relações fonte-dreno em trigo submetido a deficiência hídrica no estádio reprodutivo. Revista Brasileira de Fisiologia Vegetal, São Carlos, v.5, n.2, p.145-150, 1993.

SACCARDY, K.; CORNIC, G.; BRULFERT, J.; REYSS, A. Effect of drought stress on net $\mathrm{CO}_{2}$ uptake by Zea leaves. Planta, Berlin, v.199, n.4, p.589-595, 1996.

TURNER, N.C. Techniques and experimental approaches for the measurement of plant water status. Plant and Soil, The Hague, v.58, p.339-366, 1981. 
TURNER, N.C.; SCHULZE, E.-D.; GOLLAN, T. The responses of stomata and leaf gas exchange to vapour pressure deficits and soil water content. II. In mesophytic herbaceus species Helianthus annuus. Oecologia, Berlin, v.65, n.3, p.348-355, 1985.

WARDLAW, I.F. The early stages of grain development in wheat: response to water stress in a single variety. Australian Journal of Biological Science, Melbourne, v.24, p.1047-1055, 1971.
ZHANG, J.; DAVIS, W.J. Change in the concentration of ABA in xylem sap as a function of changing soil water status can account for changes in leaf conductance and growth. Plant, Cell and Environment, Oxford, v.13, n.3, p.277-285, 1990.

ZHANG, J.; DAVIS, W.J. Increased synthesis of ABA in partially dehydrated root tips and ABA transport from root to leaves. Journal of Experimental Botany, London, v.38, n.197, p.2015-2023, 1987. 